\title{
erratum
}

\section{A Toll-like receptor recognizes bacterial DNA}

Hiroaki Hemmi, Osamu Takeuchi, Taro Kawai, Tsuneyasu Kaisho, Shintaro Sato, Hideki Sanjo, Makoto Matsumoto, Katsuaki Hoshino, Hermann Wagner, Kiyoshi Takeda \& Shizuo Akira

Nature 408, 740-744 (2000).

Figure 1 was printed incorrectly in this paper owing to a font error.

The correct Fig. 1 is reproduced below.

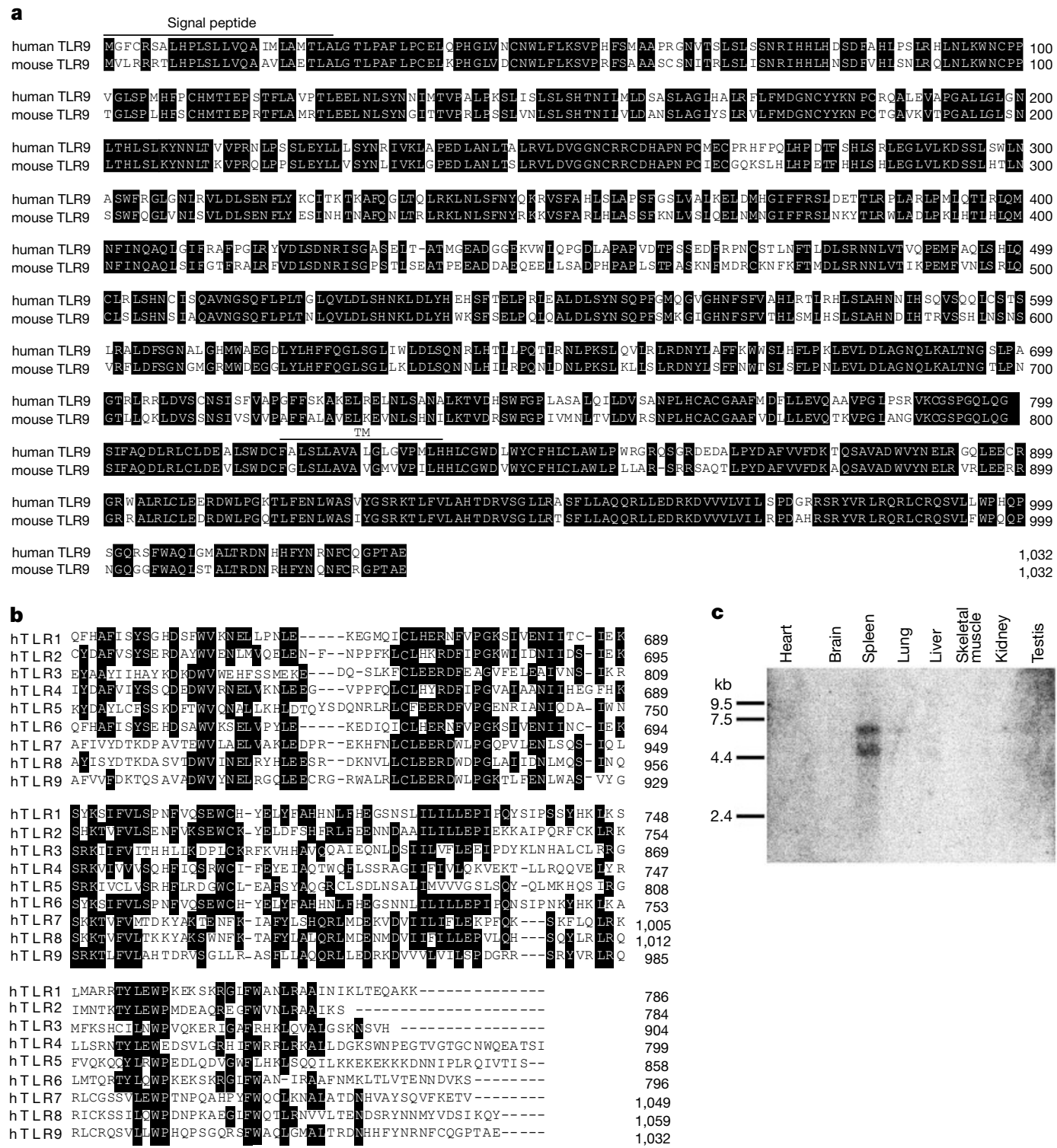

Figure 1 Amino-acid sequences and tissue distribution of TLR9. a, Alignment of human and mouse TLR9. Identical amino acids are indicated by a solid box. Human and mouse TLR9 share an overall amino-acid identity of $75.5 \%$. The predicted signal peptide (human and mouse, residues 1-25) and transmembrane segments (TM; human, 819-836; mouse, 820-837) are indicated. During the preparation of this manuscript, the sequences for human TLR9 were deposited in GenBank by two other groups (accession numbers NM017442 and AF245704). b, Alignment of the cytoplasmic domains of human TLR family members. Amino-acid residues conserved in least four molecules are highlighted by solid boxes. c, A mouse multiple-tissue northern blot (Clontech) containing $2 \mu \mathrm{g}$ of poly $(\mathrm{A})^{+}$RNA was probed with a mouse TLR9 cDNA fragment. 
1. Parekh, A. B. \& Penner, R. Store depletion and calcium influx. Physiol. Rev, 77, 901-930 (1997).

2. Connolly, T. M., Bansal, V. S., Bross, T. E., Irvine, R. F. \& Majerus, P. W. The metabolism of tris- and tetraphosphates of inositol by 5-phosphomonoesterase and 3-kinase enzymes. J. Biol. Chem. 262, $2146-2149$ (1987)

3. Irvine, R. F. \& Moor, R. M. Micro-injection of inositol 1,3,4,5-tetrakisphosphate activates sea urchin eggs by a mechanism dependent on external $\mathrm{Ca}^{2+}$. Biochem. J. 240, 917-920 (1986).

4. Morris, A. P., Gallacher, D. V., Irvine, R. F. \& Petersen, O. H. Synergism of inositol trisphosphate and tetrakisphosphate in activating $\mathrm{Ca}^{2+}$-dependent $\mathrm{K}^{+}$channels. Nature 330, 653-655 (1987).

Bird, G. S. et al. Activation of $\mathrm{Ca}^{2+}$ entry into acinar cells by a non-phosphorylatable inositol trisphosphate. Nature 352, 162-165 (1991).

6. Smith, P. M., Harmer, A. R., Letcher, A. J. \& Irvine, R. F. The effect of inositol 1,3,4,5-tetrakisphosphate on inositol trisphosphate-induced $\mathrm{Ca}^{2+}$ mobilization in freshly isolated and cultured mouse lacrimal acinar cells. Biochem. J. 347, 77-82 (2000).

7. Fukuda, M. \& Mikoshiba, K. The function of inositol high polyphosphate binding proteins. BioEssays 19, 593-603 (1997)

8. Cullen, P. J. Bridging the GAP in inositol 1,3,4,5-tetrakisphosphate signalling. Biochim. Biophys. Acta 1436, 35-47 (1998)

9. Hoth, M. \& Penner, R. Depletion of intracellular calcium stores activates a calcium current in mast cells. Nature 355, 353-356 (1992).

10. Parekh, A. B., Fleig, A. \& Penner, R. The store-operated calcium current $I_{\mathrm{CRAC}}$ : nonlinear activation by $\mathrm{InsP}_{3}$ and dissociation from calcium release. Cell 89, 973-980 (1997).

11. Broad, L. M., Armstrong, D. L. \& Putney, J. W. Role of the inositol 1,4,5-trisphosphate receptor in $\mathrm{Ca}^{2+}$ feedback Inhibition of calcium release-activated calcium current $I_{\text {CRAC. }}$ J. Biol. Chem. 274, $32881-$ 32888 (1999).

12. Glitsch, M. D. \& Parekh, A. B. $\mathrm{Ca}^{2+}$ store dynamics determines the pattern of activation of the storeoperated $\mathrm{Ca}^{2+}$ current $I_{\mathrm{CRAC}}$ in response to InsP $\mathrm{P}_{3}$ in rat basophilic leukaemia cells. J. Physiol. (Lond.) 523, 283-290 (2000)

13. Jones, S. V., Choi, O. H. \& Beaven, M. A. Carbachol induces secretion in a mast cell line (RBL-2H3) transfected with the M1 muscarinic receptor gene. FEBS Lett. 289, 47-50 (1991).

14. Lewis, R. S. \& Cahalan, M. D. Potassium and calcium channels in lymphocytes. Annu. Rev. Immunol. 13, 623-653 (1995)

15. Hirata, M. et al. Inositol 1,4,5-trisphosphate receptor subtypes differentially recognize regioisomers of D-myo-inositol 1,4,5-trisphosphate. Biochem. J. 328, 93-98 (1997).

16. Guillemette, G., Favreau, I., Lamontagne, S. \& Boulay, G. 2,3-Diphosphoglycerate is a nonselective inhibitor of inositol 1,4,5-trisphosphate action and metabolism. Eur. J. Pharmacol. 188, 251-260 (1990).

17. Safrany, S. T. et al. Design of potent and selective inhibitors of myo-inositol 1,4,5-trisphosphate 5-phosphatase. Biochemistry 33, $10763-10769$ (1994).

18. Wojcikiewicz, R. J. Type I, II, and III inositol 1,4,5-trisphosphate receptors are unequally susceptible to down-regulation and are expressed in markedly different proportions in different cell types. J. Biol. Chem. 270, 11678-11683 (1995).

19. De Smedt, H. et al. Determination of relative amounts of inositol trisphosphate receptor mRNA isoforms by ratio polymerase chain reaction. J. Biol. Chem. 269, 21691-21698 (1994).

20. Bird, G. S. \& Putney, J. W. Jr. Effect of inositol 1,3,4,5-tetrakisphosphate on inositol trisphosphateactivated $\mathrm{Ca}^{2+}$ signaling in mouse lacrimal acinar cells. J. Biol. Chem. 271, 6766-6770 (1996).

21. Communi, D., Dewaste, V. \& Erneux, C. Calcium-calmodulin-dependent protein kinase II and protein kinase C- mediated phosphorylation and activation of D-myo-inositol 1,4,5-trisphosphate 3-kinase B in astrocytes. J. Biol. Chem. 274, 14734-14742 (1999).

22. De Smedt, F. et al. Isoprenylated human brain type I inositol 1,4,5-trisphosphate 5- phosphatase controls $\mathrm{Ca}^{2+}$ oscillations induced by ATP in Chinese hamster ovary cells. J. Biol. Chem. 272, 17367 17375 (1997)

23. Parekh, A. B. \& Penner, R. Depletion-activated calcium current is inhibited by protein kinase in RBL2H3 cells. Proc. Natl Acad. Sci. USA 92, 7907-7911 (1995).

24. Hughes, A. R., Takemura, H. \& Putney, J. W. Jr. Kinetics of inositol 1,4,5-trisphosphate and inosito cyclic 1:2,4,5-trisphosphate metabolism in intact rat parotid acinar cells. Relationship to calcium signalling. J. Biol. Chem. 263, 10314-10319 (1988).

25. da Silva, C. P., Emmrich, F. \& Guse, A. H. Adriamycin inhibits inositol 1,4,5-trisphosphate 3-kinase activity in vitro and blocks formation of inositol 1,3,4,5-tetrakisphosphate in stimulated Jurkat T-lymphocytes. Does inositol 1,3,4,5-tetrakisphosphate play a role in $\mathrm{Ca}^{2+}$-entry? J. Biol. Chem. 269, 12521-12526 (1994).

26. Balla, T. et al. Agonist-induced calcium signaling is impaired in fibroblasts overproducing inositol 1,3,4,5-tetrakisphosphate. J. Biol. Chem. 266, 24719-24726 (1991)

27. Riley, A. M., Mahon, M. F. \& Potter, B. V. L. Rapid synthesis of the enantiomers of myo-inositol 1,3,4,5-tetrakisphosphate by direct chiral desymmetrization of myo-inositol orthoformate. Angew. Chem. Int. Edn. Eng. 36, 1472-1474 (1997)

28. Yoshimura, K., Watanabe, Y., Erneux, C. \& Hirata, M. Use of phosphorofluoridate analogues of D-myo-inositol 1,4,5-trisphosphate to assess the involvement of ionic interactions in its recognition by the receptor and metabolising enzymes. Cell. Signal. 11, 117-125 (1999).

29. Worley, P. F., Baraban, J. M., Supattapone, S., Wilson, V. S. \& Snyder, S. H. Characterization of inosito trisphosphate receptor binding in brain. Regulation by $\mathrm{pH}$ and calcium. J. Biol. Chem. 262, 12132 12136 (1987).

\section{Acknowledgements}

We would like to thank D. Tani and M. Monteilh-Zoller for technical assistance; C. Erneux for the InsP $\mathrm{P}_{3}$ 5-phosphatase plasmid ECH10; the Wellcome Trust for Programme Grant Support (to B.V.L.P.). We acknowledge grant support by the Ministry of Education, Science, Sports and Culture of Japan (to H.T. and M.H.), Kyushu University Interdisciplinary Programs in Education and Projects in Research Development (to M.H.) and The Naito Foundation (to M.H.)

Correspondence should be addressed to R.P. (e-mail: rpenner@hawaii.edu) and requests for materials should be addressed to B.V.L.P. (e-mail: prsbvlp@bath.ac.uk).

\section{A Toll-like receptor recognizes bacterial DNA}

\author{
Hiroaki Hemmi ${ }^{\star} \uparrow$, Osamu Takeuchi ${ }^{\star} \dagger$, Taro Kawai ${ }^{\star} \dagger$, \\ Tsuneyasu Kaisho ${ }^{\star}+$, Shintaro Sato* $\uparrow$, Hideki Sanjo ${ }^{\star}$ \\ Makoto Matsumoto ${ }^{\star} \dagger$, Katsuaki Hoshino ${ }^{\star} \dagger$, Hermann Wagner $\neq$, \\ Kiyoshi Takeda* $\uparrow \&$ Shizuo Akira ${ }^{\star} \dagger$
}

* Department of Host Defense, Research Institute for Microbial Diseases, Osaka University and † Core Research for Evolutional Science and Technology, Japan Science and Technology Corporation, 3-1 Yamada-oka, Suita, Osaka 565-0871, Japan

$\$$ Institute of Medical Microbiology, Immunology and Hygiene,

Technical University of Munich, Trogerstr. 9, D-81675 Munich, Germany

DNA from bacteria has stimulatory effects on mammalian immune cells ${ }^{1-3}$, which depend on the presence of unmethylated CpG dinucleotides in the bacterial DNA. In contrast, mammalian DNA has a low frequency of CpG dinucleotides, and these are mostly methylated; therefore, mammalian DNA does not have immuno-stimulatory activity. CpG DNA induces a strong T-helper1-like inflammatory response ${ }^{4-7}$. Accumulating evidence has revealed the therapeutic potential of CpG DNA as adjuvants for vaccination strategies for cancer, allergy and infectious diseases ${ }^{8-10}$. Despite its promising clinical use, the molecular mechanism by which CpG DNA activates immune cells remains unclear. Here we show that cellular response to CpG DNA is mediated by a Toll-like receptor, TLR9. TLR9-deficient $\left(\mathrm{TLR9}^{-/-}\right.$) mice did not show any response to CpG DNA, including proliferation of splenocytes, inflammatory cytokine production from macrophages and maturation of dendritic cells. TLR9 ${ }^{-/-}$mice showed resistance to the lethal effect of CpG DNA without any elevation of serum pro-inflammatory cytokine levels. The in vivo CpG-DNA-mediated T-helper type-1 response was also abolished in $\mathrm{TLR9}^{-1-}$ mice. Thus, vertebrate immune systems appear to have evolved a specific Toll-like receptor that distinguishes bacterial DNA from self-DNA.

The Toll-like receptor (TLR) family is a phylogenetically conserved mediator of innate immunity that is essential for microbial recognition ${ }^{11}$. Mammalian TLRs comprise a large family with extracellular leucine-rich repeats (LRRs) and a cytoplasmic Toll/ interleukin (IL)-1R (TIR) homology domain. So far, six members (TLR1-6) have been reported ${ }^{12-14}$, and two additional members have been deposited in GenBank as TLR7 and TLR8 (accession numbers AF240467 and AF246971, respectively). TLR2 and TLR4 are responsible for immune responses to peptidoglycan (PGN) and lipopolysaccharide (LPS), respectively ${ }^{15-22}$.

By using a BLAST search, we identified an expressed sequence tag (EST) clone (AA273731; mouse) that showed high similarity with the previously identified TLRs. Using this fragment as a probe, we isolated a full-length complementary DNA from the mouse macrophage cDNA library. We also isolated the human counterpart. Sequence analysis revealed the presence of regions conserved in the TLR family, such as LRR and TIR domain (Fig. 1a, b). Therefore, we designated this gene TLR9. Northern blot analysis of various tissues indicated that mouse TLR9 transcripts were most abundantly expressed in the spleen (Fig. 1c).

To assess the biological function of TLR9, we generated TLR9 ${ }^{-1-}$ mice by homologous recombination in embryonic stem (ES) cells. The targeting vector was constructed to replace a $1.0-\mathrm{kb}$ fragment of the mouse Tlr9 gene encoding a part of LRR with a neomycin resistance cassette (neo) (Fig. 2a). Correctly targeted ES cell clones were micro-injected into $\mathrm{C} 57 \mathrm{BL} / 6$ blastocysts, which contributed to transmission of the mutated allele through the germ line. We intercrossed heterozygotes to produce offspring that were homozygous for the disrupted Tlr9 allele (Fig. 2b). The mutant mice were 
born at the expected mendelian ratio. We then investigated expression of TLR9 messenger RNA in the spleen by northern blot analysis. When we used the carboxy-terminal fragment as a probe, we detected $\operatorname{Tl} 9$ transcripts from the mutant mice at almost the same size but in reduced amounts compared with those from wildtype mice (Fig. 2c). We next carried out polymerase chain reaction with reverse transcription (RT-PCR) using spleen mRNA from the mutant mice. Sequence analysis of these products showed that the transcribed Tlr9 gene contained the neo gene. The insertion of neo resulted in an appearance of a stop codon at the amino-terminal portion of TLR9, indicating that a functional TLR9 protein was not expressed in the mutant mice (Fig. 2d). TLR9 $^{-1-}$ mice showed no abnormal composition of lymphocytes as determined by flow cytometry (data not shown).

MyD88 is an adaptor molecule involved in the signalling through the IL-1R and TLR families. We previously showed that MyD88 is essential for the response to IL-1, IL-18, LPS and many other bacterial cell-wall components ${ }^{23}$. We have also shown that the responses to $\mathrm{CpG}$ DNA are dependent on MyD88 and TRAF6 (ref. 24). $\mathrm{MyD} 88^{-1-}$ mice did not respond to CpG DNA, whereas both TLR2 ${ }^{--}$and TLR $4^{-/-}$mice responded normally to CpG DNA. These data indicate that CPG DNA is recognized by TLRs other than TLR2 and TLR4. Therefore, we analysed responses of TLR9 ${ }^{-1-}$ mice to CpG DNA. We first investigated the proliferation of splenocytes in response to CpG DNA (Fig. 3a). CpG DNA, but not non-CpG DNA induced proliferation of wild-type splenocytes in a dosedependent manner. In contrast, $\mathrm{TLR}^{-1-}$ splenocytes did not proliferate in response to either CpG DNA or non-CpG DNA, although they showed a similar proliferative response to LPS as the wild-type cells. Wild-type B cells showed enhanced surface expression of major histocompatibility complex (MHC) class II in response to CpG DNA; however, a CpG-DNA-induced increase in MHC class II expression was not observed in TLR9 $^{-1-}$ B cells (data not shown). These data indicate that $\mathrm{TLR}^{-/-} \mathrm{B}$ cells are defective in

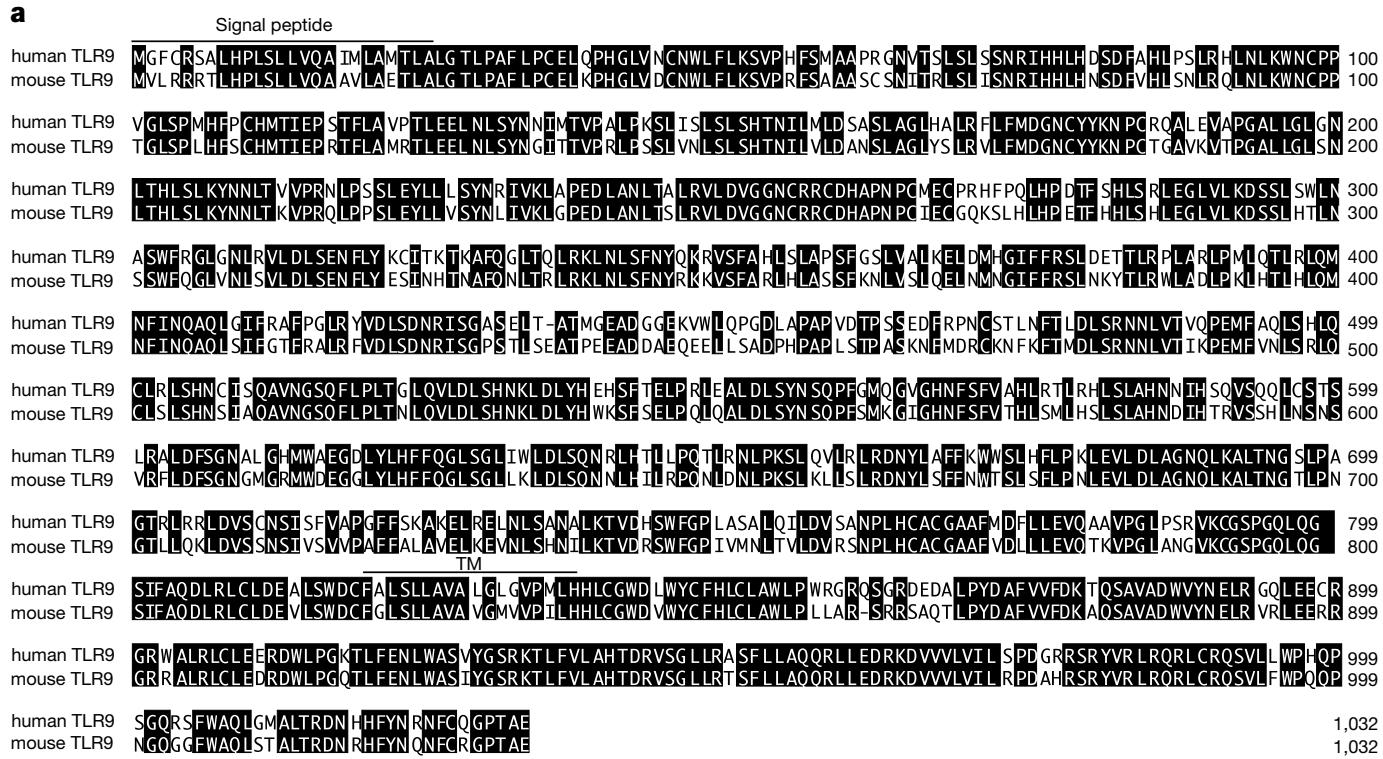

b

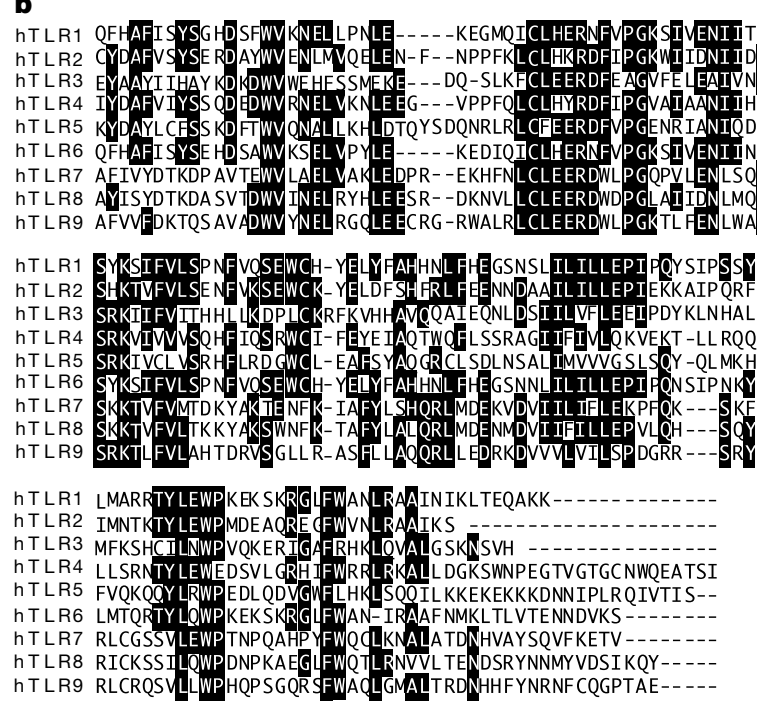

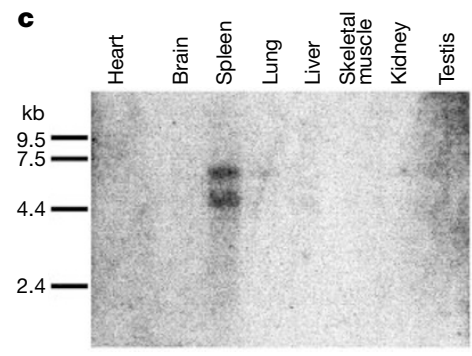

Figure 1 Amino-acid sequences and tissue distribution of TLR9. a, Alignment of human and mouse TLR9. Identical amino acids are indicated by a solid box. Human and mouse TLR9 share an overall amino-acid identity of $75.5 \%$. The predicted signal peptide (human and mouse, residues 1-25) and transmembrane segments (TM; human, 819-836; mouse, $820-837$ ) are indicated. During the preparation of this manuscript, the sequences for human TLR9 were deposited in GenBank by two other groups (accession numbers NM017442 and AF245704). b. Alignment of the cytoplasmic domains of human TLR family members. Amino-acid residues conserved in least four molecules are highlighted by solid boxes. C, A mouse multiple-tissue northern blot (Clontech) containing $2 \mu \mathrm{g}$ of poly $(\mathrm{A})^{+}$RNA was probed with a mouse TLR9 CDNA fragment. 
their response to CpG DNA.

Next, we measured production of inflammatory cytokines from peritoneal macrophages by enzyme-linked immunoabsorbent assay (ELISA; Fig. 3b). Macrophages from wild-type mice produced tumour necrosis factor (TNF)- $\alpha$, IL- 6 and IL-12 in response to CpG DNA. The production was further enhanced when stimulated with a combination of interferon (IFN) $-\gamma$ and CpG DNA. However, macrophages from $\mathrm{TLR}^{-/-}$mice did not produce any detectable levels of inflammatory cytokines in response to CpG DNA even in the presence of IFN- $\gamma$. Macrophages from wild-type and TLR9 ${ }^{-1-}$ mice produced similar amounts of TNF- $\alpha$, IL- 6 and IL-12 in response to LPS, PGN, lipoprotein from Escherichia coli, Zymosan and whole heat-killed Staphylococcus aureus (Fig. 3b; and data not shown), indicating that $\mathrm{TLR}^{-/-}$macrophages are specifically defective in their response to CpG DNA.

CpG-containing bacterial DNA is a potent stimulant for dendritic cells (DCs) to support T-helper type-1 (Th1) cell development ${ }^{4-7}$. Therefore, we examined CpG-DNA-induced cytokine production and upregulation of surface molecules in bone-marrow-derived murine DCs. Wild-type DCs produced IL-12 in response to CpG DNA; however, TLR9 ${ }^{-/}$DCs did not produce any detectable levels of IL-12 (Fig. 3c). Wild-type DCs showed enhanced surface expression of CD40, CD80, CD86 and MHC class II when stimulated with CpG DNA. TLR9 ${ }^{-1-}$ DCs did not show any enhanced expression of the surface molecules in response to CpG-DNA (Fig. 3d). Both wildtype and TLR9 ${ }^{-1-}$ DCs exhibited similar responses to LPS. Together, these findings indicate that TLR9 is essential for cellular responses to CpG DNA.

Signalling through TLRs occurs through the sequential recruitment of the adaptor molecule MyD88 and the serine/ threonine kinase IRAK, and subsequently activates mitogen-activated protein (MAP) kinases and the nuclear factor NF- $\mathrm{KB}^{23}$. We next analysed activation of the intracellular signalling cascade in response to CpG DNA. In wild-type macrophages, stimulation with CpG DNA increased the DNA-binding activity of NF- $\kappa$, as determined by electrophoretic mobility shift assay (EMSA; Fig. 3e); however, NF- $\kappa B$ activity was not increased in response to $\mathrm{CpG}$ DNA in TLR9 ${ }^{-1-}$ macrophages. LPS stimulation of $\mathrm{TLR9}^{-/-}$ macrophages led to activation of NF- $\kappa \mathrm{B}$ to the same extent as that of wild-type cells, indicating that CpG-DNA-induced activation of NF- $\mathrm{B}$ was impaired in $\mathrm{TLR}^{-1-}$ macrophages. In vitro kinase assay showed that CpG DNA activated c-Jun N-terminal kinase (JNK) and IRAK in wild-type macrophages. Activation of both kinases was completely abolished in TLR9 $^{-1-}$ macrophages (Fig. 3f, g). Thus, CpG-DNA-mediated signal transduction is dependent on TLR9.

Finally, we addressed the in vivo response to CpG DNA in TLR9 ${ }^{-1-}$ mice. CpG DNA can induce lethal shock in D-galactosamine (DGalN)-sensitized mice ${ }^{25}$. Wild-type mice died within $12 \mathrm{~h}$ after DGalN plus CpG DNA administration with marked elevation of serum concentrations of TNF- $\alpha$, IL-6 and IL-12 (Fig. 4a, b). In contrast, all TLR ${ }^{-1-}$ mice survived without any increase in serum concentration of these inflammatory cytokines. Thus, TLR9 ${ }^{-1-}$ mice were highly resistant to $\mathrm{CpG}-\mathrm{DNA}$-induced shock syndrome. In vivo administration of CpG DNA has also been shown to induce a Th1biased response ${ }^{26}$. CpG DNA and ovalbumin (OVA) were injected into the footpads, and lymph node cells were isolated at the 7-day time point and stimulated with OVA. The popliteal lymph node of

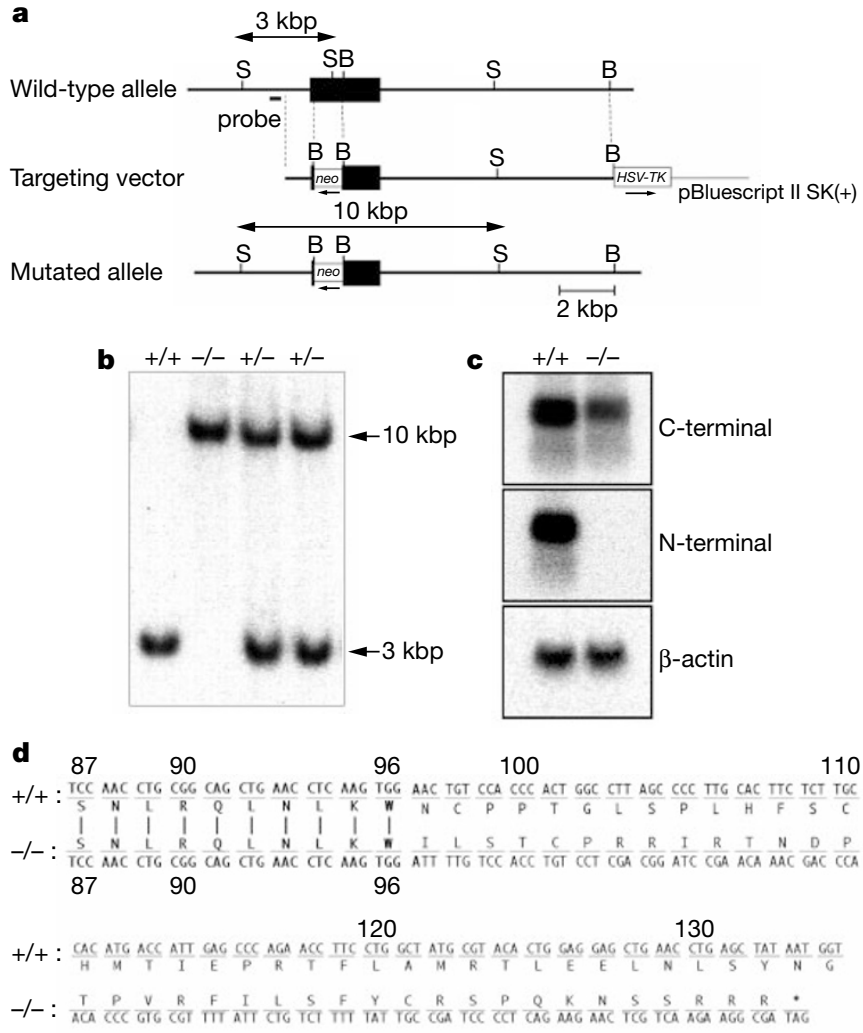

Figure 2 Targeted disruption of the mouse TIr9 gene. a, Maps of the TLR9 genome, the targeting vector and the predicted disrupted gene. Filled boxes denote the coding exon. Restriction enzymes: B, BamHI; S, Scal. b, Southern blot analysis of offspring from the heterozygote intercrosses. Genomic DNA was extracted from mouse tails, digested with $S c a l$, electrophoresed and hybridized with the radiolabelled probe indicated in $\mathbf{a}$. Southern blotting gave a single 3.0-kb band for wild-type (+/+), a 10-kb band for homozygous
$(-/-)$ and both bands for heterozygous mice (+/-). c, Northern blot analysis of splenocytes. Total RNA $(10 \mu \mathrm{g})$ extracted from splenocytes was electrophoresed, transferred to a nylon membrane, and hybridized using the TLR9 $\mathrm{C}$-terminal or $\mathrm{N}$-terminal fragment as a probe. The same membrane was rehybridized with a $\beta$-actin probe. d, Comparison of predicted amino-acid sequences between wild-type (+/+) and TLR9 ${ }^{-/}$ $(-/-)$ cDNA. The numbers indicate predicted amino-acid position of wild-type TLR9. 
CpG DNA-treated wild-type mice showed an increase in size compared with that of PBS treated mice, whereas TLR9 $^{-1-}$ mice did not show any lymphadenopathy (data not shown). Lymph node cells from CpG-DNA-treated wild-type mice produced IFN- $\gamma$ in response to OVA (Fig. 4c). In contrast, production of IFN- $\gamma$ from TLR9 $^{-/-}$lymph node cells was not observed. Thus, CpG-DNAinduced Th1-like response was not observed in $\mathrm{TLR9}^{-/-}$mice.

The nature and localization of the $\mathrm{CpG}$ receptor are controversial. There is evidence that CpG DNA binds to cell-surface receptors that subsequently transduce stimulatory signals, because Sepharose beads coated with active CpG DNA stimulate B cells as free CpG $\mathrm{DNA}^{27}$. In contrast, other reports show that internalization of the DNA is required for activity ${ }^{28}$. Inhibitors of endosomal maturation such as bafilomaycin A or chloroquine abolish CpG-mediated cell activation, indicating that cellular uptake by nonspecific endocytosis and subsequent endosomal maturation precede cell activation $^{29,30}$. Acidification of endosomal CpG DNA is coupled to the rapid generation of intracellular reactive oxygen species, followed by NF- $\kappa \mathrm{B}$ activation ${ }^{31}$. Thus, in the latter case, it has been proposed that CpG DNA works through binding to an intracellular receptor. The presence of a transmembrane segment in the TLR9 gene strongly suggests that TLR9 is inserted into the membrane, but not present in the cytoplasm. Although the localization of TLR9 awaits assessment by immunostaining, confocal data show that tagged MyD88 colocalizes with tagged CpG DNA in endosomal structures, but not at the cell membrane (H.W., unpublished data). In contrast, LPS colocalizes with MyD88 at the cell membrane. This suggests that signalling is triggered by LPS at the cell membrane, whereas CpG DNA initiates signalling after translocation to endosomes. This assumption may well correlate with the finding that CpG-DNA-induced IRAK activation is delayed as compared with that stimulated with LPS (Fig. 3g). The identification of CpG DNA signalling receptor will pave the way to understanding the mechanism by which CPG DNA is recognized as well as by which the recognition of CpG DNA is translated into a strong Th1 response. Furthermore, $\mathrm{TLR}^{-/-}$mice will provide a useful model for clarifying to what extent recognition of CpG DNA contributes to host immune responses against bacterial infections.
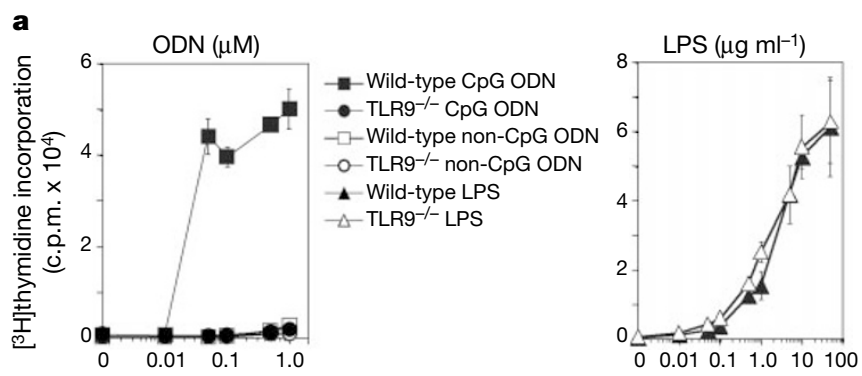

b
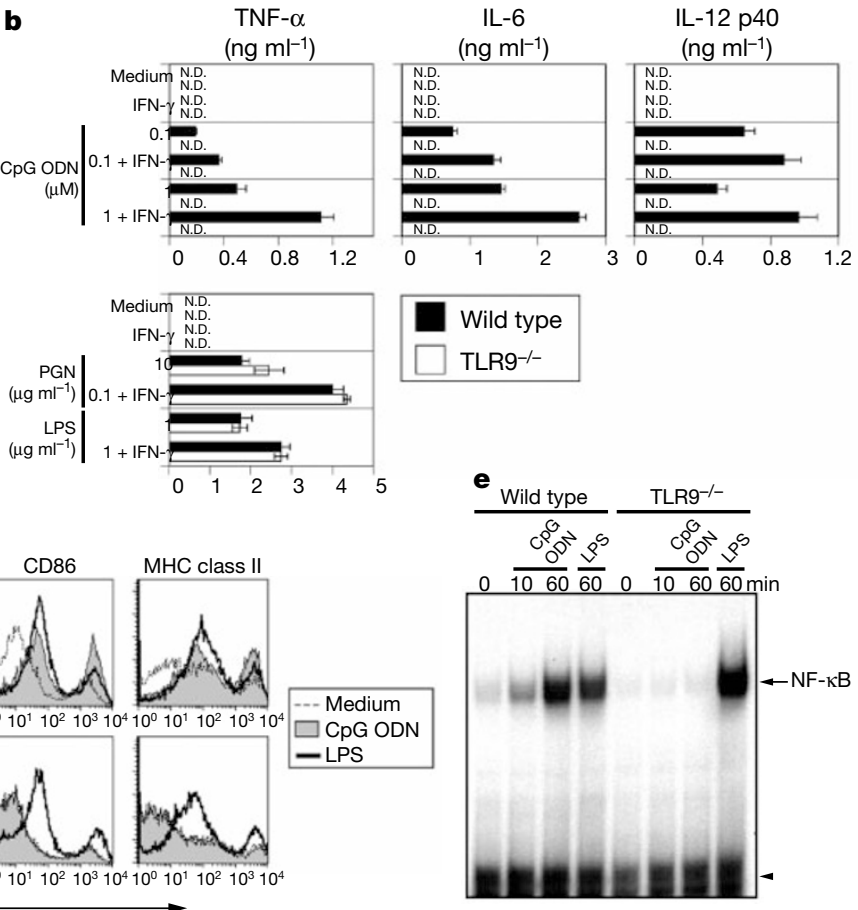

C

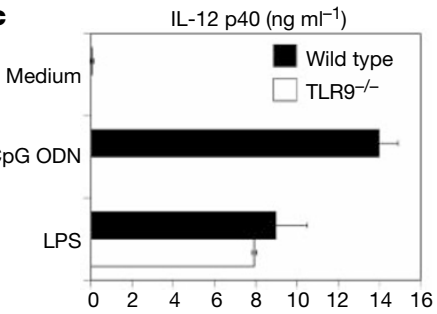

d
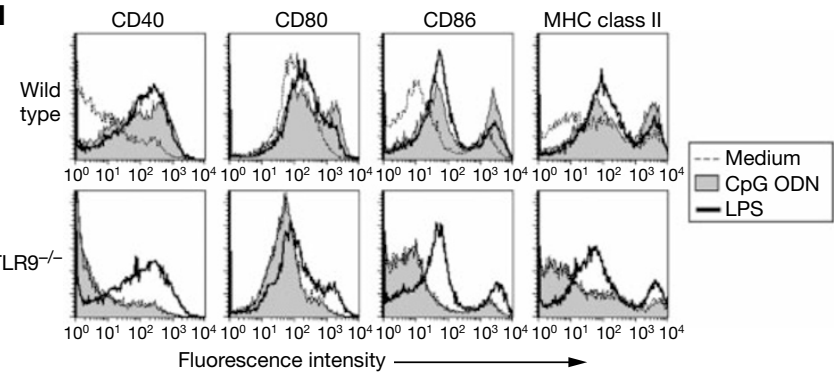
- LPS $\rightarrow$

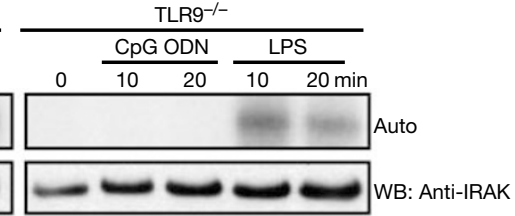

f
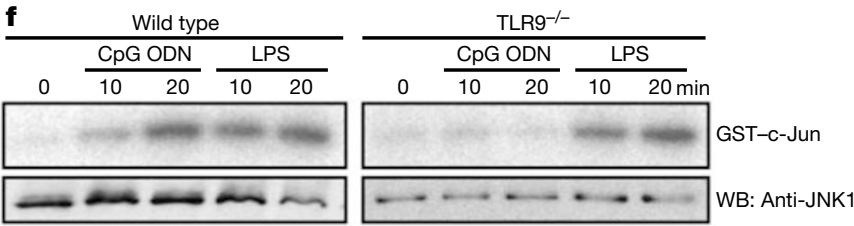

Figure 3 Impaired responses to CpG ODN in TLR9 ${ }^{-/-}$cells. a, Splenocytes from wild-type or $\mathrm{TLR}^{-1-}$ mice were cultured with the indicated concentrations of $\mathrm{CpG} \mathrm{ODN}$, non-CpG ODN or LPS for $48 \mathrm{~h}$ plus pulsed $\left[{ }^{3} \mathrm{H}\right]$ thymidine for the last $8 \mathrm{~h}$. $\left[{ }^{3} \mathrm{H}\right]$ thymidine incorporation was measured by $\beta$-scintillation counting. Data indicate mean \pm s.d. of triplicate samples of one representative experiment. $\mathbf{b}$, Peritoneal macrophages from wild-type or $\mathrm{TLRg}^{-/}$ mice were stimulated with CpG ODN $(0.1$ or $1.0 \mu \mathrm{M})$, PGN $\left(10 \mu \mathrm{g} \mathrm{ml}^{-1}\right)$ or LPS $(1.0 \mu \mathrm{g} \mathrm{ml}$ $\left.{ }^{-1}\right)$ in the presence or absence of $30 \mathrm{U} \mathrm{ml}^{-1} \mathrm{IFN}-\gamma$ for $24 \mathrm{~h}$, and concentrations of TNF- $\alpha$, IL-6 and IL-12 p40 in the culture supernatants were measured by ELISA. Similar results were obtained from three independent experiments. Data indicate mean \pm s.d. N.D., not detected. c, Wild-type or $\mathrm{TLR}^{-/-}$dendritic cells (DCs) derived from bone marrow were cultured with $\mathrm{CpG}$ ODN or LPS. Concentrations of IL-12 p40 in culture supernatants were measured by ELISA. Data indicate mean \pm s.d. d, DCs were stimulated with CpG ODN or

\section{g}

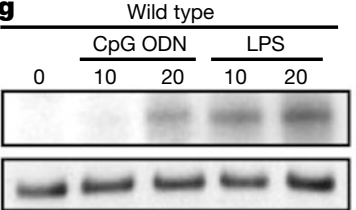

LPS for $48 \mathrm{~h}$ and analysed for cell-surface expression of the indicated molecules by flow cytometry. e, Peritoneal macrophages from wild-type and $\mathrm{TLRG}^{-1-}$ mice were stimulated with 1.0 $\mu \mathrm{M} \mathrm{CpG} \mathrm{ODN}$ or $1.0 \mu \mathrm{g} \mathrm{ml}^{-1} \mathrm{LPS}$ for the indicated durations. NF- $\mathrm{KB}$ activity was determined by EMSA. Arrow indicates the inducible NF- $\mathrm{\kappa B}$ complex; arrowhead indicates free probe. f, Peritoneal macrophages from wild-type and $\mathrm{TLRG}^{-/}$mice were stimulated with 1.0 $\mu \mathrm{M} \mathrm{CpG}$ ODN or $1.0 \mu \mathrm{g} \mathrm{ml}^{-1} \mathrm{LPS}$ for the indicated durations. Cell lysates were prepared and immunoprecipitated with anti-JNK antibody. JNK activity was measured by in vitro kinase assay using a GST-c-Jun fusion as a substrate (top). The same lysates were blotted with anti-JNK (bottom). $\mathbf{g}$, The same cell lysates in $\mathbf{f}$ were immunoprecipitated with anti-IRAK antibody. The kinase activity of IRAK was measured by in vitro kinase assay (top). The same lysates were blotted with anti-IRAK antibody (bottom). Auto, autophosphorylation. 


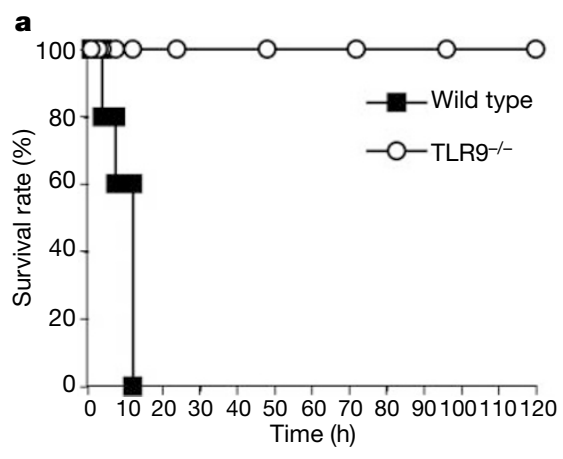

b
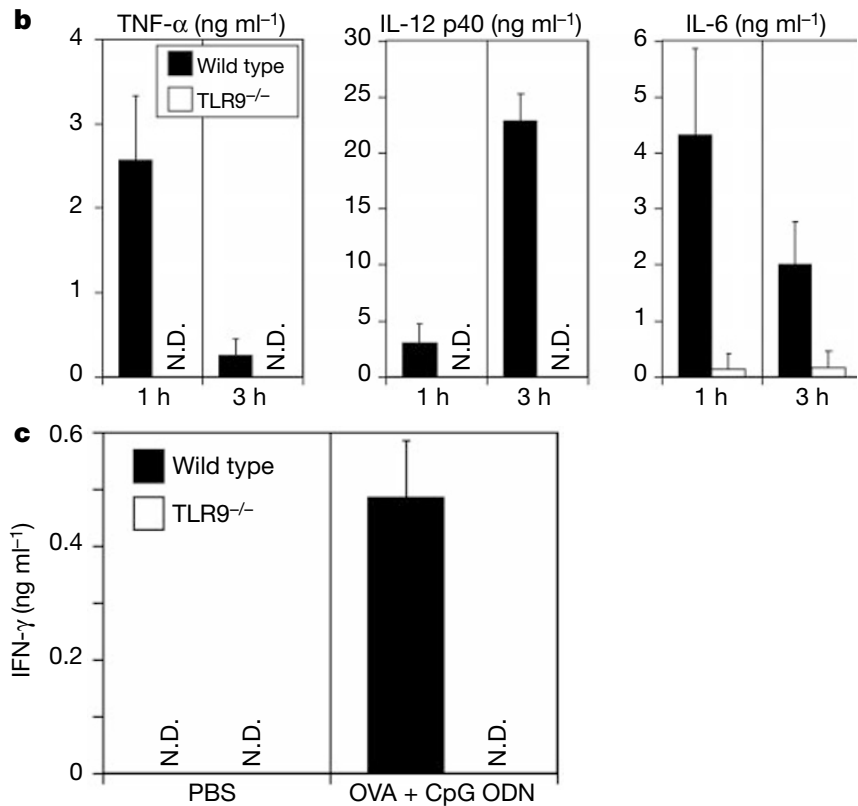

Figure 4 Resistance to $\mathrm{CpG}$ ODN-induced shock in TLR9 ${ }^{-/}$mice. a, Age-matched wildtype $(n=5)$ and $\mathrm{TLRG}^{-/-}$mice $(n=5)$ were intraperitoneally injected with $\mathrm{CpG}$ ODN (20 nmol) and D-GalN (20 mg). Survival was monitored for $5 \mathrm{~d}$. b. Wild-type and $\mathrm{TLRg}^{-1-}$ mice were intraperitoneally injected with $\mathrm{CpG} O \mathrm{DN}$ and $\mathrm{D}$-GalN. Sera were taken at 1 or $3 \mathrm{~h}$ after injection. Serum concentrations of TNF- $\alpha, \mathrm{IL}-12 \mathrm{p} 40$ and IL- 6 were measured by ELISA. N.D., not detected. Results are mean of sera samples from three mice. c, Agematched wild-type and $\mathrm{TLRg}^{-/}$mice were injected with PBS or CpG ODN (5 nmol) plus OVA $(150 \mu \mathrm{g})$ into the hind footpads. Popliteal lymph node cells were collected after $7 \mathrm{~d}$ and cultured with OVA for $24 \mathrm{~h}$. Production of IFN- $\gamma$ from lymph node cells was analysed by ELISA. Data indicate mean \pm s.d. N.D., not detected.

\section{Methods}

\section{Cloning of TLR9}

A GenBank search resulted in identification of a mouse EST that has a significant similarity with human TLR4. Using PCR-amplified EST as a probe, a full-length cDNA clone containing the complete TLR9 open reading frame was isolated from the mouse RAW 264.7 cDNA library. Human genomic sequence that showed significant homology with the mouse TLR9 gene was found in GenBank. On the basis of this sequence, rapid amplification of cDNA ends protocol was performed to isolate full-length cDNA from U937 cDNA library.

\section{Generation of TLR9 $^{-1-}$ mice}

The TLR9 genomic DNA was isolated from 129/Sv mouse genomic library and characterized by restriction enzyme mapping and sequencing analysis. The targeting vector was constructed by replacing a 1.0-kb fragment encoding a part of LRR region with a neomycin-resistance gene cassette (neo), and a herpes simplex virus thymidine kinase driven by $\mathrm{MCl}$ promoter was inserted into the genomic fragment for negative selection (Fig. 2a). The targeting vector was transfected into embryonic stem cells (E14.1). G418 and gancyclovir doubly resistant colonies were selected and screened by PCR and southern blotting. Homologous recombinants were micro-injected into C57BL/6 blastocysts. Chimaeric mice were mated with $\mathrm{C} 57 \mathrm{BL} / 6$ female mice, and heterozygous $\mathrm{F}_{1}$ progenies were intercrossed in order to obtain $\mathrm{TLR}^{-/-}$mice. All mice analysed here were $\mathrm{F}_{1}$ progeny of $129 / \mathrm{Ola} \times \mathrm{C} 57 \mathrm{BL} / 6$.

\section{Reagents}

Phosphorothioate-stabilized CpG oligodeoxynucleotide (ODN) (TCC-ATG-ACG-TTCCTG-ATG-CT $)^{28}$ was purchased from TIB MOLBIOL or Hokkaido System Science. Phosphorothioate-stabilized non-CpG ODN (GCT-TGA-TGA-CTC-AGC-CGG-AA) ${ }^{5}$ was purchased from Hokkaido System Science. LPS from Salmonella minnesota Re-595 and PGN from Staphylococcus aureus were purchased from Sigma and Fluka, respectively ${ }^{21}$.

\section{Measurement of cytokine production from macrophages}

Thioglycollate-elicited peritoneal macrophages were cultured with the indicated concentrations of CpG ODN, LPS or PGN for $24 \mathrm{~h}$. Concentrations of TNF- $\alpha$, IL- 6 and IL-12 $\mathrm{p} 40$ in the culture supernatants were measured by ELISA.

\section{Preparation and analysis of dendritic cells}

Bone-marrow cells from wild-type or TLR9 ${ }^{-/}$mice were cultured with $10 \mathrm{ng} \mathrm{ml}^{-1}$ mouse granulocyte macrophage-colony stimulating factor (Peprotech) in RPMI1640 medium supplemented with $10 \%$ fetal bovine serum. At day 6 , immature DCs were collected and cultured in the absence or presence of $0.1 \mu \mathrm{M} \mathrm{CpG} \mathrm{ODN} \mathrm{or} 0.1 \mu \mathrm{g} \mathrm{ml}^{-1}$ LPS in a fresh medium for a further 2 days. The concentration of IL-12 p40 in the culture supernatants was measured by ELISA. DCs were stained with biotinylated antibodies against CD40, CD80, CD86 or MHC class II, and developed with PE-conjugated streptavidin. Flow cytometric analysis was performed using a FACSCalibur with CELLQuest software (Becton Dickinson).

\section{EMSA and in vitro kinase assay}

Thioglycollate-elicited peritoneal macrophages $\left(1 \times 10^{6}\right.$ cells $)$ from wild-type and TLR9 ${ }^{-/-}$ mice were stimulated for the indicated periods and then nuclear proteins were extracted. The extracts were incubated with a specific probe containing NF-кB DNA-binding sites, electrophoresed and visualized by autoradiography.

Thioglycollate-elicited peritoneal macrophages were stimulated with $1.0 \mu \mathrm{M}$ CpG ODN or $1.0 \mu \mathrm{g} \mathrm{ml}^{-1}$ LPS for the indicated periods. JNK and IRAK activities in cell lysates were measured by in vitro kinase assays as described ${ }^{23}$.

\section{Cytokine production of presensitized lymph nodes}

Age-matched wild-type and $\mathrm{TLR}^{-/-}$mice were injected subcutaneously with CpG ODN $(5 \mathrm{nmol})$ plus soluble OVA $(150 \mu \mathrm{g})$ into the hind footpads. Seven days later, popliteal lymph nodes were collected and cultured with $100 \mu \mathrm{g} \mathrm{ml}^{-1}$ OVA for $24 \mathrm{~h}$. Concentrations of IFN- $\gamma$ in the culture supernatants were measured by ELISA.

Received 26 June; accepted 3 October 2000.

1. Krieg, A. M. Lymphocyte activation by CpG dinucleotide motifs in prokaryotic DNA. Trends Microbiol. 4, 73-76 (1996)

2. Lipford, G. B., Heeg, K. \& Wagner, H. Bacterial DNA as immune cell activator. Trends Microbiol. 6, 496-500 (1998).

3. Yamamoto, S., Yamamoto, T. \& Tokunaga, T. The discovery of immunostimulatory DNA sequence. Spring. Ser. Immunopathol. 22, 11-19 (2000).

4. Jakob, T., Walker, P. S., Krieg, A. M., Udey, M. C. \& Vogel, J. C. Activation of cutaneous dendritic cells by CPG-containing oligodeoxynucleotides: a role for dendritic cells in the augmentation of Th1 responses by immunostimulatory DNA. J. Immunol. 161, 3042-3049 (1998).

5. Sparwasser, T. et al. Bacterial DNA and immunostimulatory $\mathrm{CpG}$ oligonucleotides trigger maturation and activation of murine dendritic cells. Eur. J. Immunol. 28, 2045-2054 (1998).

6. Hartmann, G., Weiner, G. J. \& Krieg, A. M. CpG DNA: a potent signal for growth, activation, and maturation of human dendritic cells. Proc. Natl Acad. Sci. USA 96, 9305-9310 (1999).

7. Häcker, H. et al. Cell type-specific activation of mitogen-activated protein kinases by CPG-DNA controls interleukin-12 release from antigen-presenting cells. EMBO J. 18, 6973-6982 (1999).

8. Wagner, H. Bacterial CpG DNA activates immune cells to signal infectious danger. Adv. Immunol. 73, 329-368 (1999).

9. Klinman, D. M., Verthelyi, D., Takeshita, F. \& Ishii, K. J. Immune recognition of foreign DNA: a cure for bioterrorism? Immunity 11, 123-129 (1999).

10. Krieg, A. M. The role of CpG motifs in innate immunity. Curr. Opin. Immunol. 12, 35-43 (2000).

11. Medzhitov, R. \& Janeway, C. A. Jr Innate immunity: the virtues of a nonclonal system of recognition. Cell 91, 295-298 (1997).

12. Medzhitov, R., Preston-Hurlburt, P. \& Janeway, C. A. Jr A human homologue of the Drosophila Toll protein signals activation of adaptive immunity. Nature 388, 394-397 (1997).

13. Rock, F. L., Hardiman, G., Timans, J. C., Kastelein, R. A. \& Bazan, J. F. A family of human receptors structurally related to Drosophila Toll. Proc. Natl Acad. Sci. USA 95, 588-593 (1998).

14. Takeuchi, O. et al. TLR6: A novel member of an expanding toll-like receptor family. Gene 231, 59-65 (1999)

15. Poltorak, A. et al. Defective LPS signaling in $\mathrm{C} 3 \mathrm{H} / \mathrm{HeJ}$ and C57BL/10ScCr mice: mutations in $\mathrm{Tlr} 4$ gene. Science 282, 2085-2088 (1998).

16. Hoshino, K. et al. Toll-like receptor 4 (TLR4)-deficient mice are hyporesponsive to lipopolysaccharide: evidence for TLR4 as the Lps gene product. J. Immunol. 162, 3749-3752 (1999).

17. Yoshimura, A. et al. Recognition of Gram-positive bacterial cell wall components by the innate immune system occurs via Toll-like receptor 2. J. Immunol. 163, 1-5 (1999).

18. Brightbill, H. D. et al. Host defense mechanisms triggered by microbial lipoproteins through toll-like receptors. Science 285, 732-736 (1999).

19. Aliprantis, A. O. et al. Cell activation and apoptosis by bacterial lipoproteins through Toll-like receptor-2. Science 285, 736-739 (1999).

20. Underhill, D. M. et al. The Toll-like receptor 2 is recruited to macrophage phagosomes and discriminates between pathogens. Nature 401, 811-815 (1999). 
21. Takeuchi, O. et al. Differential roles of TLR2 and TLR4 in recognition of gram-negative and grampositive bacterial cell wall components. Immunity 11, 443-451 (1999).

22. Takeuchi, O. et al. Preferentially the R-stereoisomer of the mycoplasmal lipopeptide macrophageactivating lipopeptide-2 activates immune cells through a toll-like receptor 2- and MyD88-dependen signaling pathway. J. Immunol. 164, 554-557 (2000).

23. Kawai, T., Adachi, O., Ogawa, T., Takeda, K. \& Akira, S. Unresponsiveness of MyD88-deficient mice to endotoxin. Immunity 11, 115-122 (1999).

24. Häcker, H. et al. Immune cell activation by bacterial CpG-DNA through myeloid differential marker 88 and tumor necrosis factor receptor-associated factor (TRAF)6. J. Exp. Med. 192, 595-600 (2000).

25. Sparwasser, T. et al. Macrophages sense pathogens via DNA motifs: induction of tumor necrosis factor- $\alpha$-mediated shock. Eur. J. Immunol. 27, 1671-1679 (1997).

26. Lipford, G. B. et al. CpG-DNA-mediated transient lymphadenopathy is associated with a state of Thl predisposition to antigen-driven responses. J. Immunol. 165, 1228-1235 (2000).

27. Liang, H., Reich, C. F., Pisetsky, D. S., Lipsky, P. E. The role of cell surface receptors in the activation of human B cells by phosphorothioate oligonucleotides. J. Immunol. 165, 1438-1445 (2000).

28. Krieg, A. M. et al. CpG motifs in bacterial DNA trigger direct B-cell activation. Nature 374, 546-549 (1995).

29. Macfarlane, D. E. \& Manzel, L. Antagonism of immunostimulatory CpG-oligodeoxynucleotides by quinacrine, chloroquine, and structurally related compounds. J. Immunol. 160, 1122-1131 (1998).

30. Häcker, H. et al. CpG-DNA-specific activation of antigen-presenting cells requires stress kinase activity and is preceded by non-specific endocytosis and endosomal maturation. EMBO J. 17, 62306240 (1998)

31. Yi, A. K. \& Krieg, A. M. Rapid induction of mitogen-activated protein kinases by immune stimulatory CpG DNA. J. Immunol. 161, 4493-4497 (1998).

\section{Acknowledgements}

We thank G. B. Lipford for helpful discussions; T. Aoki for secretarial assistance; and N. Tsuji, N. Iwami and E. Nakatani for technical assistance. We also thank Hayashibara Biochemical Laboratories, Inc. for providing anti-IRAK antibody. This work was supported in part by grants from the Ministry of Education, Science, Sports and Culture of Japan, and Research Fellowships of the Japan Society for the Promotion of Science for Young Scientists.

Correspondence and requests for materials should be addressed to S.A.

(e-mail: sakira@biken.osaka-u.ac.jp). Sequences have been deposited in GenBank under accession numbers AB045180 and AB045181 for human and mouse TLR9, respectively.

\section{Structure of the bacteriophage $\phi 29$} DNA packaging motor

\author{
Alan A. Simpson ${ }^{\star} \dagger$, Yizhi Tao ${ }^{\star} \dagger \neq$, Petr G. Leiman*, \\ Mohammed O. Badasso $\$$, Yongning He*, Paul J. Jardine $\|$, \\ Norman H. Olson ${ }^{\star}$, Marc C. Morais ${ }^{\star}$, Shelley Grimes $\S$, \\ Dwight L. Anderson $\$, Timothy S. Baker ${ }^{\star}$ \& Michael G. Rossmann
}

* Department of Biological Sciences, Purdue University, West Lafayette, Indiana 47907-1392, USA

$\$$ Departments of Microbiology and Oral Science, 18-246 Moos Tower,

University of Minnesota, Minneapolis, Minnesota 55455, USA

II Department of Biology, University of New Brunswick, Fredericton,

New Brunswick E3B 6E1, Canada

$\dagger$ These authors contributed equally to this work

Motors generating mechanical force, powered by the hydrolysis of ATP, translocate double-stranded DNA into preformed capsids (proheads) of bacterial viruses ${ }^{1,2}$ and certain animal viruses ${ }^{3}$. Here we describe the motor that packages the double-stranded DNA of the Bacillus subtilis bacteriophage $\phi 29$ into a precursor capsid. We determined the structure of the head-tail connector-the central component of the $\phi 29$ DNA packaging motor-to $3.2 \AA$ resolution by means of $\mathrm{X}$-ray crystallography. We then fitted the connector into the electron densities of the prohead and of the partially packaged prohead as determined using cryo-electron microscopy and image reconstruction analysis. Our results suggest that the prohead plus dodecameric connector, prohead RNA, viral ATPase and DNA comprise a rotary motor with the

末 Present address: Department of Molecular and Cellular Biology, Harvard University, 7 Divinity Avenue Cambridge, Massachusetts 02138, USA head-prohead RNA-ATPase complex acting as a stator, the DNA acting as a spindle, and the connector as a ball-race. The helical nature of the DNA converts the rotary action of the connector into translation of the DNA.

The bacteriophage $\phi 29$ (Fig. 1) is a 19-kilobase (19-kb) doublestranded DNA (dsDNA) virus with a prolate head and complex structure $^{4}$. The prohead (Fig. 1), into which the DNA is packaged, is about $540 \AA$ long and $450 \AA$ wide ${ }^{5}$. The $\phi 29$ connector, a coneshaped dodecamer of gene product 10 (gp10), occupies the pentagonal vertex at the base of the prohead ${ }^{5}$ and is the portal for DNA entry during packaging and DNA ejection during infection ${ }^{6}$. The connector, in association with the oligomeric, $\phi 29$-encoded prohead RNA (pRNA) and a viral ATPase (gp16), is required for DNA packaging $^{7-9}$. However, only the first 120 bases of the 174-base pRNA are essential for packaging ${ }^{7}$. The covalent adduct of the genomic dsDNA with gp3 (DNA-gp3) can be packaged into proheads in about three minutes in vitro (P.J.J., unpublished results). The connector proteins of tailed phages ${ }^{6}$ vary in relative molecular mass $\left(M_{\mathrm{r}}\right)$ from $36,000(36 \mathrm{~K})$ in $\phi 29$ to $83 \mathrm{~K}$ in phage $\mathrm{P} 22$, and assemble into oligomers with a central channel. The structure of the isolated $\$ 29$ connector has been studied by atomic force microscopy ${ }^{10}$ and cryo-electron microscopy (cryo-EM) of twodimensional arrays ${ }^{11}$, immuno-electron microscopy ${ }^{12}$ and X-ray crystallography ${ }^{13,14}$.

The connector structure, as now determined by X-ray crystallography, can be divided into three, approximately cylindrical regions: the narrow end, the central part, and the wide end, having external radii $(\AA)$ of 33, 47 and 69, respectively (Fig. 2). These regions are respectively 25,28 and $22 \AA$ in height, making the total connector $75 \AA$ long. The internal channel has a diameter of about $36 \AA$ at the narrow end, increasing to $60 \AA$ at the wide end. Comparison with electron microscopy reconstructions ${ }^{5,11}$ shows that the narrow end protrudes from the portal vertex of the phage head, is associated with the multimeric pRNA, and binds the lower collar in the mature virus.

The electron density of the connector was interpreted in terms of the amino-acid sequence ${ }^{15}$ and was confirmed by the two $\mathrm{Hg}$ sites (see Methods section) corresponding to the only cysteine residues in the sequence. Residues 1 to 11,229 to 246 , and 287 to 309 at the carboxy terminus are not seen in the electron density. The second and third disordered regions are both located on the inside of the channel, close to the junction of the central and wide regions. The structure is dominated by three long helices $(\alpha 1, \alpha 3$ and $\alpha 5)$ in each monomer that run the length of the central region, joining the two end domains of the connector (Fig. 2). These helices are arranged at an angle of about $40^{\circ}$ with respect to the central 12 -fold axis. The two end domains are composed predominantly of $\beta$-sheets and extended polypeptide chains. Immuno-electron microscopy mapping of the sequence onto the connector surface ${ }^{12}$ is consistent with the X-ray structure only as far as localization of the external aminoterminal residues with the pRNA-binding region at the narrow end of the connector. The RNA recognition motif structure, previously predicted for the $\mathrm{N}$-terminal regions of the connector monomer ${ }^{16,17}$, is not present in the structure.

The surface of the monomer presents a net negative charge to one neighbour and a net positive charge to the other neighbour, possibly aiding the assembly of the dodecamer. The exterior of the connector has no significant regions of charge accumulation, implying that its rotation might be facilitated by its oily, smooth, external surface. However, the basic character of the disordered 11 amino-terminal residues could alter the surface properties to some extent and may facilitate interaction with the pRNA. In contrast, the inside of the channel has a preponderance of negative charge at its wide end, which may repel the DNA, permitting its smooth passage during packaging and ejection. The channel through which messenger RNA is translocated in reoviruses has similar properties ${ }^{18}$.

We have determined the structures of four distinct types of $\$ 29$ 